\title{
Mobilidade e qualidade espacial urbana no entorno de terminais do sistema BRT de Curitiba: desenho urbano e condições socioambientais
}

\author{
Mobility and urban space quality in the environment of terminals of the \\ Curitiba BRT system: urban design and socio-environmental conditions
}

Cristina de Araújo Lima ${ }^{[0]}$, Rafaela Antunes Fortunato ${ }^{[b]}$

[a] Universidade Federal do Paraná (UFPR), Curitiba, PR, Brasil

[b] Universidade Tecnológica Federal do Paraná (UTFPR), Curitiba, PR, Brasil

\section{Resumo}

\begin{abstract}
O presente artigo propõe uma reflexão a respeito das características de espaços urbanos situados nas proximidades de sistema de transporte, partindo do pressuposto de que um projeto de Desenho Urbano não atinge completamente seu objetivo sem uma avaliação da obra realizada. É necessário saber como aquele espaço projetado se apresenta após determinado tempo de uso e assimilação pela sociedade, considerando estes locais como itens definidos por projeto e regidos por legislação urbanística. Assim, o artigo relata o início de uma pesquisa que busca, inicialmente, entender as características morfológicas, funcionais e socioambientais do entorno de terminais centrais do sistema BRT de Curitiba - uma proposta curitibana reproduzida mundialmente. No estudo são focalizadas quadras, lotes, atividades e equipamentos existentes nas proximidades de alguns terminais. Nessa etapa preliminar foi testada uma metodologia baseada em sistema de pontuação derivado de seis categorias de análise definidas por características diversas aplicadas aos dados coletados em campo e provenientes de fontes secundárias. Os resultados apontam aspectos que sinalizam possibilidades de maior adensamento, diversidade de usos, serviços, equipamentos na perspectiva de consolidação de centralidades vinculadas ao Sistema BRT; evidenciam condições socioambientais como itens secundários, confirmando terminais centrais como concentradores das funções urbanas de uso cotidiano.
\end{abstract}

Palavras-chave: Desenho urbano. Qualidade espacial urbana. Mobilidade e uso do solo. Espaço entorno terminais BRT. Curitiba.

CAL é Arquiteta Urbanista, Doutora em Meio Ambiente e Desenvolvimento, e-mail: cristinadearaujolima@gmail.com RAF é Arquiteta Urbanista, Doutora em Meio Ambiente e Desenvolvimento, e-mail: rafortunato@utfpr.edu.br 


\section{Abstract}

The present article proposes a reflection about the characteristics of urban spaces located in the proximities of a transportation system, assuming that an Urban Design project does not reach its objective completely without an evaluation of the work done. It is necessary to know how that projected space presents after a certain time of use and assimilation by the society, considering these places as items defined by project and governed by urbanistic legislation. Thus, the article reports the beginning of a research that initially seeks to understand the morphological, functional and socio environmental characteristics of the central terminal environment of the Curitiba BRT system - a proposal reproduced worldwide. In the study are focused blocks, lots, activities and equipment existing in the vicinity of some terminals. In this preliminary stage, a methodology based on scoring system derived from six categories of analysis defined by diverse characteristics applied to the data collected in the field and from secondary sources was tested. The results point to aspects that indicate possibilities of greater densification and diversity of uses, services, equipment in the perspective of consolidation of centralities linked to the BRT System; they put in evidence socio environmental conditions as secondary items, confirming central terminals as hubs of urban functions of daily use.

Keywords: Urban design. Urban space quality. Mobility and land use. Surroundings space BRT terminals. Curitiba.

\section{Introdução}

O conteúdo do artigo é integrante de um debate mais abrangente que aborda as condições mutantes das cidades e suas populações, como discute Mongin (2013), incluindo as possibilidades de promoção de sustentabilidade da cidade compacta versus difusa (Neuman, 2014; Nilsson et al., 2014) e, como motor da expansão urbana, a dependência do uso do automóvel. Entende-se que as cidades podem ser direcionadas para processos de maior sustentabilidade (Amado, 2009; Freyman, 2012; Kates et al., 2005; Palomo, 2005), e um dos itens é o uso do transporte coletivo ao invés do veículo individual, prática disseminada globalmente (Kenworthy \& Laube, 1999). Os Eixos Estruturais de Curitiba foram propostos em 1966 para facilitar o uso do transporte coletivo, uma prática cotidiana para $45 \%$ da população atual (PMC, 2016). A sua forma tentacular, em cinco direções, tem características para distribuir o transporte público nas diferentes áreas da cidade. No entanto, se pressupõe que os usuários do transporte coletivo não habitam nos eixos destinados a tal serviço, o que seria mais sustentável. Assim, se questionam as características do espaço urbano produzido ao longo dos Eixos Estruturais, sobretudo nos terminais, que operam como sub-centros, do ponto de vista funcional (Vallejo \&
Farrerons, 2002), socioambiental (Santos, 2004; Tucci \& Bertoni, 2003) e, com suporte de Lynch (1997), a legibilidade traduzida em marcos urbanos como item crucial no espaço urbano.

$\mathrm{Na}$ análise do espaço urbano, um dos fatores que inicialmente se evidencia é a forma, um dos fatores determinantes da qualidade do espaço, como defende Allain: "a forma não é tudo, mas ela não é negligenciável" (2004, p. 5), ao que reitera Kohlsdorf: "A forma dos lugares é o meio mais importante de emissão de informações para a realização do conceito de espaço [...] e de seu comportamento topoceptivo (Kohlsdorf, 1996, p. 72). Cassirer acrescenta uma ancoragem no pensamento de Descartes ao dizer que:

de acordo com os pressupostos básicos da metafísica cartesiana, não se pode definir de modo claro e distinto a 'coisa', ou seja, o objeto empírico, senão por meio de suas determinações puramente espaciais. A extensão de comprimento, largura e profundidade é o único predicado objetivo por meio do qual podemos determinar o objeto da experiência (Cassirer, 2011, p. 245).

0 objeto do estudo adotado focaliza a configuração do espaço urbano para a mobilidade pelo conceito de mobilidade como condição em que se 
realizam os deslocamentos de pessoas e cargas no espaço urbano (Brasil, 2012), espaços estes objeto do Urbanismo, entendido a partir do pensamento de Ascher (2010) como um conjunto de técnicas e de conhecimentos utilizados para estudar, planejar, construir e administrar cidades, desde a pequena até a grande escala. Nesse contexto, os elementos como a densidade, a diversidade de usos, a forma e detalhes influenciam o bem-estar do usuário, como salientam Daniels \& Mulley (2011). Assim, para redirecionar os procedimentos de uso do espaço, se assume a necessidade de conhecer o estado existente e, portanto, questionar o Desenho Urbano, entendido como Nobre (2011): citando Jonathan Barnett (1982), ao afirmar que Desenho Urbano é "o processo de desenhar as cidades, sem desenhar os seus edifícios". Para Choay (2006) estudar o urbano hoje é uma necessidade mesmo que a cidade tenha morrido, pois o urbano vive, persiste em formas diversificadas, analisáveis por sua morfologia. Apreende-se de Lamas (2000) o conceito de morfologia como o estudo da configuração e da estrutura exterior de um objeto e, no meio urbano, sua configuração exterior.

Concordando com Costa (2007) sobre a multidisciplinaridade dos estudos de morfologia, na pesquisa em pauta é adotado o viés do arquiteto urbanista na observação da realidade. Para Kohlsdorf (1996), citando Trieb \& Schmidt (1996), há duas categorias-síntese de observação configurativa da cidade: a que abrange o meio natural e a que abrange a tridimensionalidade, a representação do espaço urbano em projeções ortogonais (plantas e cortes) e outra categoria complementar de elementos como o mobiliário urbano e outros (comunicação, propaganda, etc.). As seis categorias morfológicas para a autora abrangem desde o sítio físico, a malha, a relação das edificações em tipos e em conjuntos. E além dos aspectos funcionais, se considera o que Hertzberger (1999, p. 174) afirma que:

Tudo o que projetamos deve ser adequado a cada situação que surja; em outras palavras, não deve ser apenas confortável, mas também estimulante - e é esta adequação fundamental e ativa que eu gostaria de designar como "forma convidativa": a forma que possui mais afinidade com as pessoas.
A questão do transporte e da expansão urbana também pode ser vista sob a perspectiva da base energética, suas limitações e alternativas, que inclui os combustíveis, e o custo da ampliação do espaço urbanizado com a implantação de infraestrutura e equipamentos, geralmente com a destruição da cobertura vegetal, canalização e poluição de corpos hídricos. Este viés socioambiental reforça a reorientação do desenho urbano, sendo um dos focos a diminuição dos deslocamentos motorizados (Pouyanne, 2004; Mongin, 2013) e também a concepção bioclimática do espaço público. Romero (2001) afirma que um dos aspectos fundamentais da abordagem que busca adequar as condições biológicas do clima ao contexto urbano é a relação de insolação dos edifícios, que afetam tanto a iluminação quanto a exposição solar de estruturas urbanas. Para Mascaró (1996) em regiões subtropicais - como é o caso da cidade de Curitiba - o sol está baixo no inverno e alto no verão. Essa situação é problemática para o ambiente construído, sobretudo no inverno, pois o sol estando mais baixo em áreas de grande adensamento, com edifícios em altura lado a lado, ocorre um sombreamento excessivo devido à projeção de sombras entre os edifícios. Os aspectos relacionados com insolação inadequada se constituem exatamente no caso dos Setores Estruturais de Curitiba. A consolidação da ocupação desses setores materializou um desenho urbano marcante, englobando mobilidade e adensamento populacional, em zonas verticalizadas de alta densidade, situadas ao longo das vias estruturais de transporte coletivo. Contudo, conforme Campos (2005, p. 159):

em busca do rápido adensamento e consolidação, o processo de ocupação do Setor Estrutural de Curitiba foi guiado por incentivos oferecidos através de diversas alterações na legislação vigente. Além dos altos coeficientes de aproveitamento e da possibilidade de implantação da edificação sem qualquer afastamento das divisas.

Esta questão acarretou sérios problemas bioclimáticos do espaço público, com sombreamento excessivo causado pela proximidade das edificações, verticalizadas sobre a estrutura fundiária antiga, prevista para baixa densidade. 
Após cerca de 30 anos da aprovação da proposta dos eixos lineares, houve a entrada em vigor da Lei 9800/00, e Curitiba passou a adotar um afastamento das divisas nos setores estruturais relacionado com a altura da edificação, denominado $\mathrm{H} / 6$, ou seja, se um edifício tiver $30 \mathrm{~m}$ de altura deve ter um afastamento da divisa de $5 \mathrm{~m}$ no mínimo, esse parâmetro está auxiliando a reduzir os efeitos de sombreamento dos edifícios em altura (Campos, 2005). Além dos aspectos relacionados ao desenho urbano, um novo contexto sociopolítico está se configurando como demonstraram os movimentos ocorridos a partir de 2013 em que a população, notadamente a urbana, vem demonstrando nas ruas a demanda por ética e melhores condições de vida. Na reflexão aqui proposta, se incluem o que está postulado no Estatuto da Metrópole (Lei 13.089/2015), tendo em vista a possibilidade de continuidade e ampliação do sistema BRT para os municípios vizinhos à capital curitibana, como em parte já existe, pela Rede Integrada de Transporte - RIT. O sistema de transporte coletivo de Curitiba foi inovador e reinterpretado em diversos municípios brasileiros e estrangeiros (PMC, 2016). Allaire (2006) salientava que o BRT criado em Curitiba era exemplo de inovação ao corresponder a valores do desenvolvimento sustentável, capacidade de deslocamento, baixo custo, sendo solução interessante para países desenvolvidos ou em desenvolvimento. Mas como o sistema repercute no espaço ao seu redor?

A rede integrada RIT foi originada nos anos 1980, e é prevista sua ampliação no contexto metropolitano (COMEC, 2006), o que pode representar um desafio quando não há uma avaliação das consequências espaciais, relativas ao Desenho Urbano decorrente da implantação do sistema BRT. Uma "Grande Curitiba" de escala metropolitana se impôs principalmente após os anos 1990, quando a consolidação do anel urbano central se efetivou agregando 14 municípios, e passou a haver maior crescimento populacional fora de Curitiba (IBGE, 1996). Ao longo do tempo, houve grande valorização econômica dos imóveis nas áreas mais centrais de Curitiba, notadamente nos eixos estruturais onde a infraestrutura é mais completa, provocando exclusão social e um espraiamento da mancha de ocupação urbana da capital sobre territórios municipais vizinhos da
Região Metropolitana de Curitiba. Esse avanço da ocupação urbana, além de acarretar crescimento das demandas por infraestrutura, equipamentos e serviços, também representa riscos socioambientais, principalmente de esgotamento de mananciais de abastecimento público (Lima, 2000), assim como também de aumento de áreas sujeitas a inundações devido à impermeabilização do solo e sobrecarga na rede de drenagem (Tucci \& Bertoni, 2003).

Este sistema implantado em 1974, foi inovador não somente como sistema de transporte coletivo, mas como fator estruturante para suporte do desenho linear da cidade, progressivamente implantado em cinco eixos. Atualmente, o sistema de transporte coletivo possui 2 milhões e trezentos mil usuários diários (PMC, 2016). No conjunto que atende a região metropolitana são $72 \mathrm{~km}$ de canaletas exclusivas para ônibus em Curitiba, que conectam os 29 terminais da cidade e os 14 localizados nos 13 municípios vizinhos que integram a Rede Integrada de Transporte RIT, ver Figura 1 (Bispo Neto, 2013; PMC, 2016). Para a análise do espaço urbano no entorno dos terminais foram aplicados procedimentos metodológicos, sintetizados a seguir, com a análise de quatro terminais de transporte que concentram o maior volume de usuários, os quais se encontram em destaque na Figura 1.

\section{Considerações metodológicas}

A pergunta de pesquisa "como entender as características morfológicas, funcionais e socioambientais do entorno dos terminais centrais do sistema BRT de Curitiba?" se constituiu no ponto de partida para a delimitação do método. Sendo o objetivo da pesquisa responder à questão em pauta, para a definição da estratégia de pesquisa foram consideradas quatro condições: o tipo da questão proposta a ser investigada; a extensão do controle dos pesquisadores sobre os eventos em pauta; o grau de enfoque na situação contemporânea, em oposição a fatos históricos e a disponibilidade de recursos humanos e financeiros, com referência de Dresch et al. (2015) e Yin (2005). Verificou-se que o objeto de estudo pressupõe a análise da relação entre elementos (unidades espaciais) e fenômenos (usos e atividades) mais do que dos objetos em si, o que conduz a uma formalização metodológica na 
Figura 1 - Rede integrada de transportes da RMC com destaque para os terminais avaliados na pesquisa

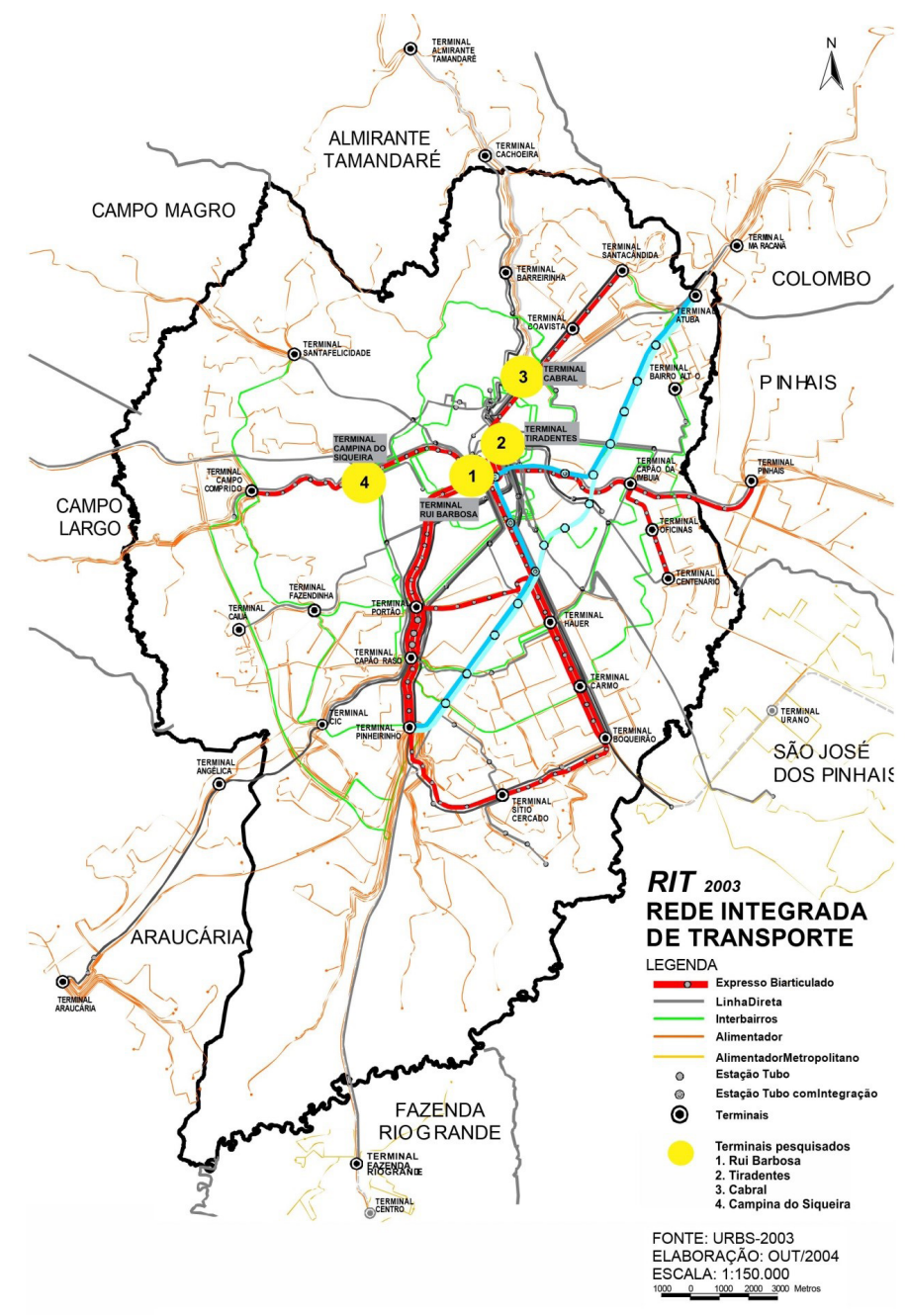

Fonte: Adaptado de Curitiba (2004).

linha do estruturalismo, que privilegia o aspecto relacional, desfocando do conteúdo para privilegiar as relações existentes no recorte em análise, como postula Demo (1995). Essa percepção levou à exclusão de outras estratégias de investigação como o experimento, a survey ou o estudo de caso. 0 estudo de caso, por exemplo, de acordo com Yin (2005) se aplica a estudos cujo problema de pesquisa seja formado por questões na forma "qual/ quais", apesar de que a presente pesquisa também inclui investigação na forma "quanto" (quantidade de usuários, de áreas, de densidades, etc.). Portanto, se constituiu um arcabouço metodológico de fases diferenciadas porém concatenadas, iniciando com uma revisão e discussão das principais referencias do marco teórico, seguido de uma fase exploratória com levantamentos de campo e pesquisa na Internet. Seguiram-se estudos explanatórios de análise realizadas com apoio de programas computadorizados e fase interpretativa com aplicação dos critérios de análise (Demo, 1995; Yin, 2005). Como método de abordagem foi adaptado o método hipotético-dedutivo a partir da pergunta de pesquisa e do pressuposto e, pelo processo de inferência dedutiva, se buscou analisar e concluir sobre a ocorrência de elementos e condições e relações morfológicas, funcionais e socioambientais que caracterizassem o entorno dos terminais de ônibus, ou das praças-terminais, como subcentros, e as diferenças de uso e ocupação do solo nas quadras circundantes. Optou-se pelo método comparativo para os procedimentos de manipulação dos dados obtidos, o que permitiu a análise por elementos determinados de forma 
original em relação ao espaço urbano (Marconi \& Lakatos, 2004). Adotou-se como pressuposto que as intervenções que implantaram os terminais urbanos responderam primeiramente às necessidades do sistema de mobilidade por transporte coletivo por ônibus. Secundariamente, os terminais foram tratados como subcentros de bairro, ou pontos nodais do espaço, segundo um partido que defende a natureza arquitetônica da cidade (Curitiba, 2004) e que propicia o questionamento acerca da qualidade desse espaço criado no entorno dos terminais.

A pesquisa possui características qualitativa-quantitativas ao buscar entender as características de um espaço urbano determinado, desde suas condições locacionais, as determinantes legais, socioambientais, morfológicas e de referenciais espaciais, ou seja, entender o espaço conforme ele está sendo construído pelas pessoas, como um artefacto social que se concretiza sobre um substrato material, e requer uma análise qualitativa (Flick, 2009). Por outro lado, são utilizados também dados quantitativos (demográficos, quantidades de usuários, de áreas disponíveis, de equipamentos, etc.), compondo um conjunto de técnicas destinadas a responder questões que configuraram a problematização da pesquisa, sendo algumas delas as seguintes:

- A zona em que se localiza o terminal apresenta diversidade de usos que favoreça menor necessidade de deslocamento dos moradores?

- 0 terminal se situa em área com mais infraestrutura ou próxima dela?

- Qual é a densidade populacional do recorte, e sua posição comparativamente à cidade?

- Com que número de pavimentos e variedade de usos as edificações atendem aos diferentes usos previstos, como residencial, comercial, serviços etc.?

- Como se apresentam os recursos naturais existentes no local (corpos d'água abertos, canalizados, margens de rios assoreadas, desmatamento, erosão, etc.), e a situação quanto a problemas socioambientais (ocupações informais em áreas de proteção; ocorrência de inundações, impermeabilidade do solo, etc.)?

- Quanto à circulação de ônibus, quais os quantitativos de linhas e de ônibus diários, principalmente nos horários de pico - 07h30/08h30 e $18 \mathrm{~h} / 19 \mathrm{~h}$ ?

- Há a presença de usos geradores de tráfego de veículos e de pessoas?

- Quais os equipamentos e serviços de educação, saúde, cultura, lazer, segurança e cidadania que podem ser acessados pelo terminal?

- Há comércio de grande porte no local?

- E quanto aos elementos espaciais, existem marcos urbanos que facilitem a identificação, a localização, ou auxiliem na comunicação do caráter do local ou edificação-referência?

- Como se apresenta o sistema viário e demais elementos de suporte à mobilidade urbana no local? Há facilidades ou dificuldades para a mobilidade a pé ou por bicicleta?

Para ler, analisar e entender as características morfológicas, funcionais e socioambientais do entorno dos terminais centrais do sistema BRT de Curitiba, o conjunto dos elementos observados foi organizado em 6 categorias de análise, recebendo o peso como produto da "Escala de Valores" formada pela aplicação das referências teóricas, que tinham sido base da definição das categorias, com destaque para Kohlsdorf (1996), Lima (2010, 2015). São eles: 1. Identificadores - Localização - Zoneamento - Área (12 pontos); 2. Demografia e densidade (12 pontos); 3. Base natural e tratamento antrópico (12 pontos); 4. Circulação de ônibus e foco gerador de tráfego (20 pontos); 5. Equipamentos e serviços (20 pontos); 6. Elementos espaciais - Forma, referência visual e de mobilidade (20 pontos). Cada um desses grupos é formado por uma série de elementos totalizando 52 itens observados no espaço ${ }^{1}$, conforme desenvolvido por Lima $(2010,2015)$.

A qualidade espacial urbana tem como unidade de análise o espaço construído do entorno de terminais do Sistema BRT de Curitiba. E nesse

\footnotetext{
1 Maiores detalhamentos sobre a metodologia aplicada, bem como sobre cada um dos 52 itens observados em campo, podem ser consultados no artigo "Configuração urbana e o sistema BRT de Curitiba - Brasil (Lima, 2010, 2015).
}

urbe. Revista Brasileira de Gestão Urbana (Brazilian Journal of Urban Management), 2017, 9(Supl. 1), 329-345 
âmbito aplicados dois critérios para a escolha dos locais a serem levantados: centralidade da localização (Arrais, 2005; Frugoli Junior, 2000) e tipo do terminal (em praças tradicionais e semi-fechados). Também foi definido o raio de abrangência que teria o recorte de estudo dos locais, adotando-se $250 \mathrm{~m}$ como raio de abrangência do recorte na presente pesquisa. Esta distância é adotada pelo Instituto de Pesquisa e Planejamento Urbano de Curitiba (IPPUC) há décadas, considerando práticas dos moradores e consta da Lei Municipal n. 12.597/2008 que dispõe sobre a organização do Sistema de Transporte Coletivo Municipal, no Artigo 4․․ Este artigo trata da Cobertura Espacial das linhas de ônibus e a localização das paradas. Essa distância de 500 metros corresponde também à relação de tempo de deslocamento entre as paradas de ônibus desenvolvida por Silveira (2012), com base em Alter.

Também foram considerados os vínculos entre critérios com as aspirações sociais, e dependendo do julgamento o item foi considerado bom, médio ou péssimo. A análise dos resultados aplicou critérios internos indicados por Demo para o trabalho científico em ciências sociais, que são: coerência (sem utilizar premissas conflituantes ou conclusões incongruentes entre si); consistência (uso de argumentação lógica e persistente no tempo); originalidade (produção não-repetitiva); objetivação (pela tentativa de entender a realidade, e descrevê-la como se apresenta, analisando os resultados com base em teorias, excluindo segundo preferências pessoais), (Demo, 1995, p. 20). A validade dos resultados é prevista como o procedimento de verificar, confrontar, teorizar, com base em Flick, o que será feito nas etapas subsequentes, em elaboração. Esse autor indica questões como: a) os resultados são baseados em dados? b) a amostragem é adequada? c) os dados são avaliados de forma coerente com o referencial teórico? d) as inferências são lógicas? e outras (Flick, 2009, p. 37). Nesse mesmo sentido, Robson (2011) recomenda interrogar os resultados quanto ao verdadeiro estado das coisas, e das relações assumidas a partir dos resultados. A validade do constructo tem embasamento na indagação apontada por Robson (2011): "isso mede ou avalia o que se pensa que mede ou avalia"? No caso dos terminais, como explicado anteriormente neste texto, se analisa um recorte-básico de 250 metros de raio, adotado pelos órgãos públicos da área e definido em legislação municipal.

Finalmente, cabe considerar que esta pesquisa utiliza uma metodologia em construção, pela qual na presente etapa foram utilizados critérios de pesos atribuídos segundo conceituação teórica. Para Chatfield \& Collins (1992) se pode começar com dados multivariados preliminares e posteriormente evoluir até chegar a conclusões do método utilizado e projeção de cenários. Como se pretende um trabalho essencialmente focado na análise de espaço urbano (e não o desenvolvimento de modelo matemático), a análise multicritério prevista terá aplicação tendo como referência o entendimento de que: "a análise multi critério tem se mostrado uma ferramenta importante quando, na avaliação de cenários e na tomada de decisão, se utilizam vários critérios ou indicadores, qualitativos e/ou quantitativos combinados de forma a fornecer uma ideia mais aproximada da situação" (Campos \& Ramos, 2005, apud Prevedello, 2014, p. 54).

Quanto aos materiais, foram também utilizadas fotos digitais como recursos da pesquisa subsidiando a análise. A seguir, os dados coletados em campo e em pesquisa na Internet (dados secundários de instituições públicas) foram compilados em tabela Excel e processados no programa Sketch-up, nos formatos: planta e elevação, com legenda dos usos existentes, conforme apresentado nas Figuras 2 e 3.

Uma síntese do encadeamento das fases da pesquisa é apresentada de forma gráfica, com aplicação do método de Ciclo de Projeto (Design Cycle) descrito por Dresch et al. (2015, p. 80) no Gráfico 1.

As Figuras 2 e 3 apresentam exemplos de representações gráficas elaboradas em computador, como descrito anteriormente, em forma de planta, corte, elevação e perspectiva dos recortes de estudo.

As informações e conclusões da pesquisa podem ser incorporadas no processo de desenvolvimento de projeto de Desenho Urbano. No caso da síntese do encadeamento das fases de projeto apresentada no Gráfico 1 (com aplicação do método de Ciclo de Projeto ou Design Cycle, descrito por Dresch et al. (2015, p. 80), essa contribuição se dará nas fases iniciais (1 e 2) e na fase final (5). 
Figura 2 - Rede integrada de transportes da RMC com destaque para os terminais avaliados na pesquisa

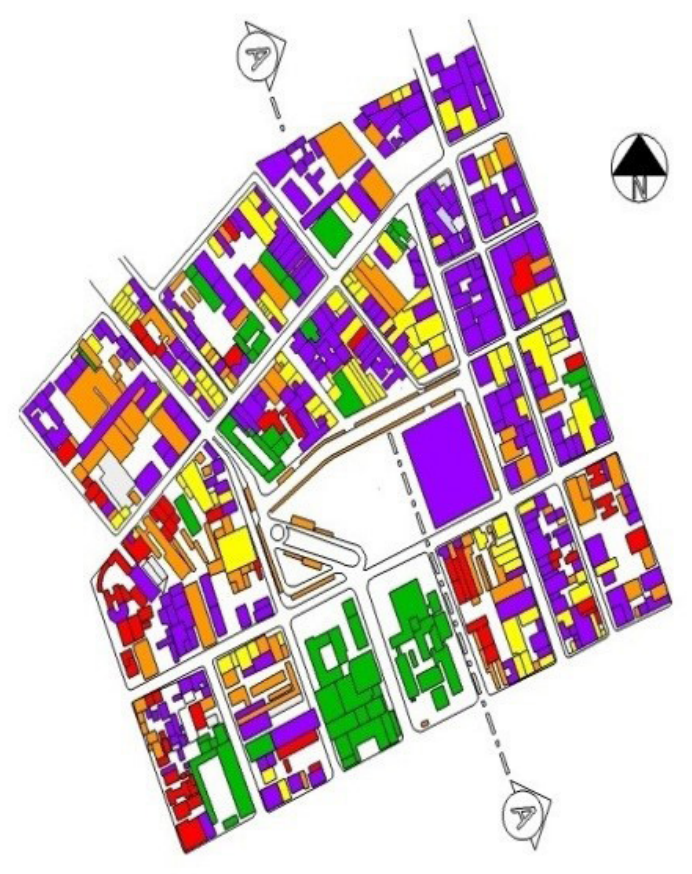

\begin{tabular}{|l|}
\hline USO DAS \\
EDIFICAÇÕES NO \\
ENTORNO DO PONTO \\
RESIDENCIAL \\
COMERCIAL \\
\hline SERVIÇOS \\
$\square$ INSTITUCIONAL \\
$\square$ LAZER \\
INDUSTRIAL \\
MISTO \\
\hline SEM USO \\
\hline
\end{tabular}
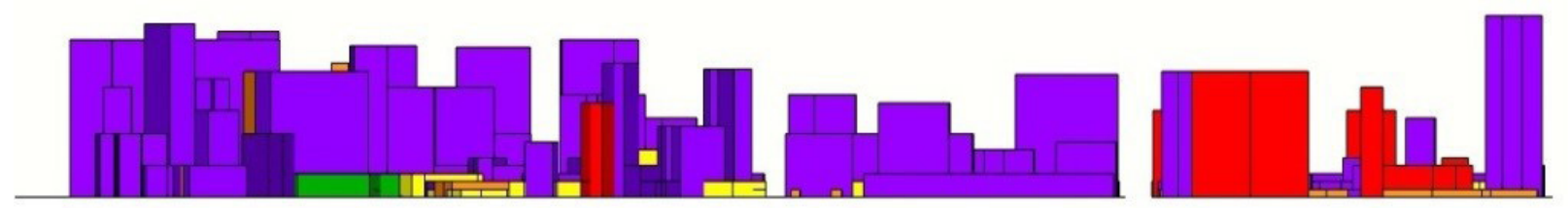

Fonte: Cara, 2014.

Figura 3 - Curitiba - Praça Rui Barbosa - Perspectiva aérea

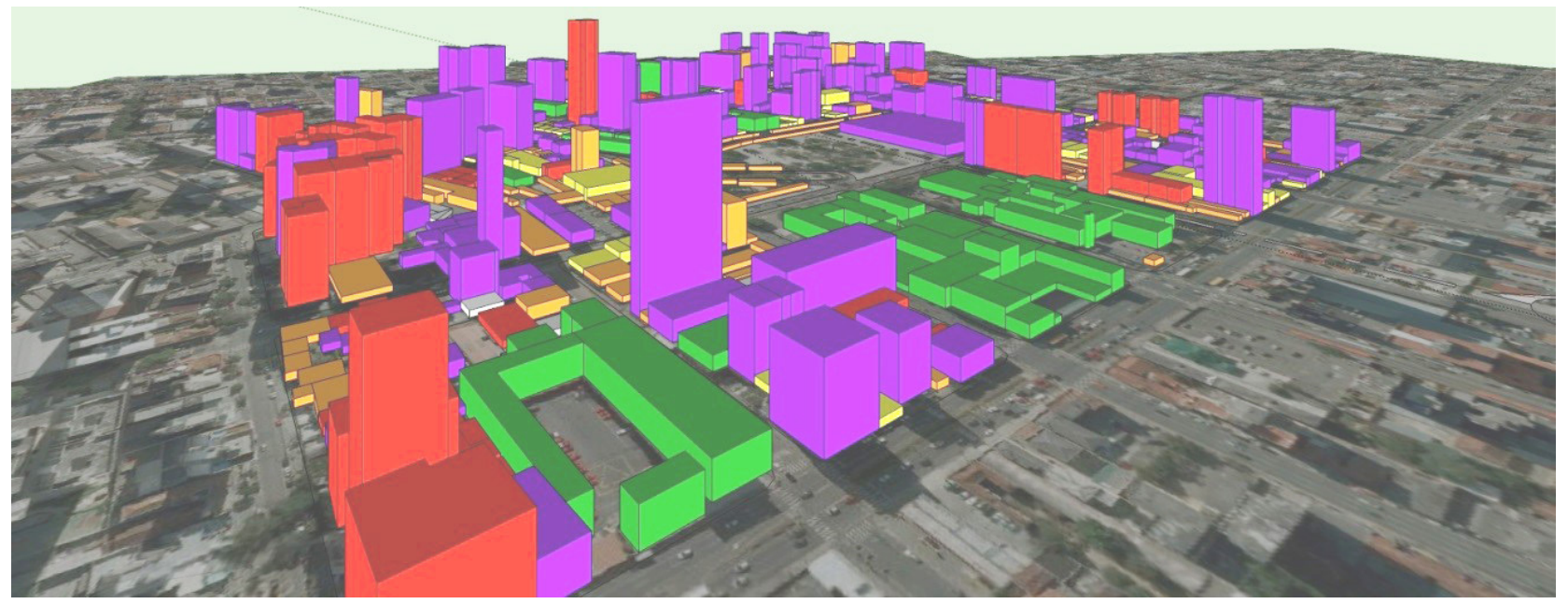

Fonte: Cara, 2014. 
Gráfico 1 - Síntese das etapas de Desenho Urbano

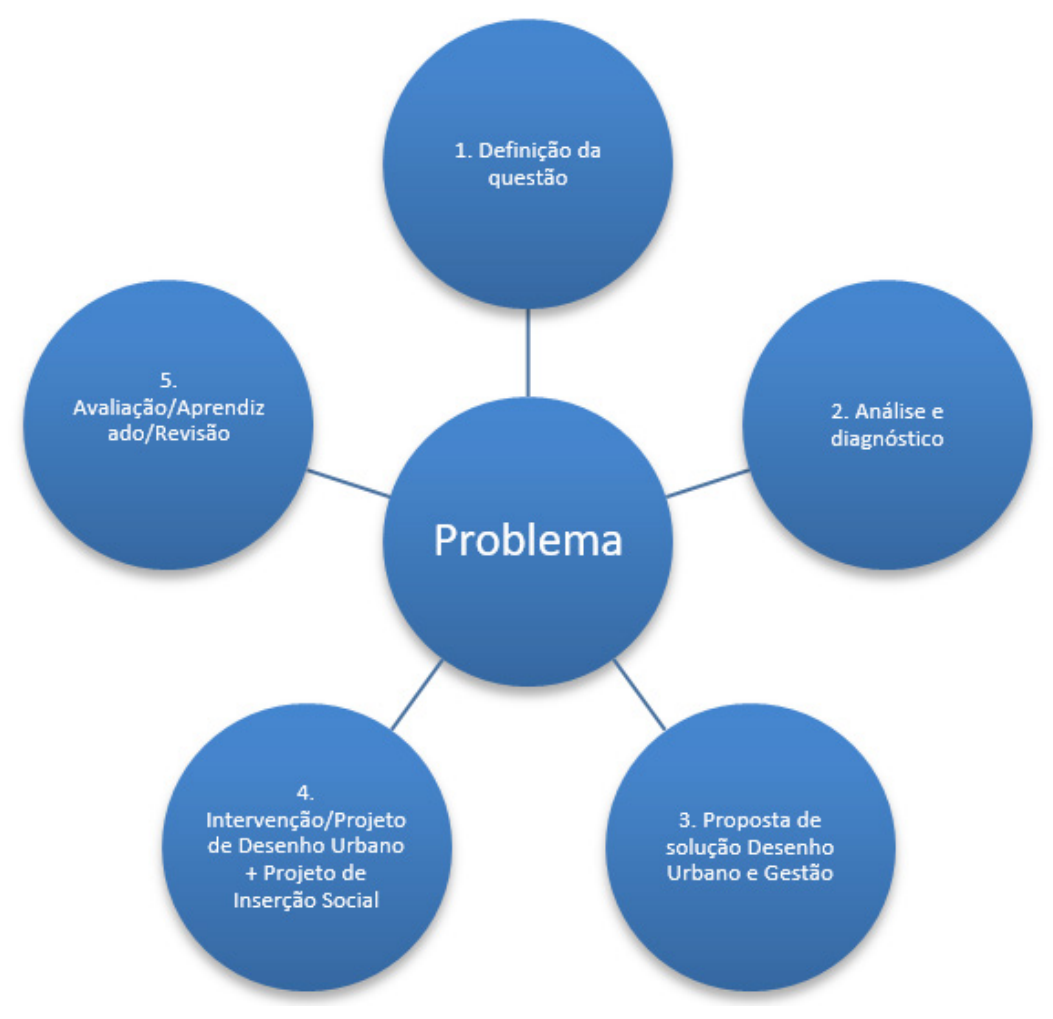

Fonte: Elaboração própria com base em Dresch et al. $(2015$, p. 80).

\section{Síntese dos resultados}

Aplicando a metodologia definida para responder à pergunta de pesquisa, foram considerados os critérios e conceitos anteriormente explicados para os quatro recortes de estudo: Praça Rui Barbosa, Praça Tiradentes, Terminal do Cabral e Terminal do Campina do Siqueira, segundo as seis categorias. As categorias e pesos foram sintetizados no formato de quadro, em que as colunas indicam os locais e os pontos recebidos, e as linhas apresentam os critérios, por categoria. $\mathrm{Na}$ tabela 1 são apresentados os pontos atribuídos para cada item das seis categorias de análise.

Dos dados apresentados no Tabela 1, organizados por categorias, se observa que: quanto à localização, os locais que se situam a menos de $1,5 \mathrm{~km}$ do marco zero da cidade foram mais valorizados, por supostamente serem mais acessíveis a equipamentos e serviços de interesse coletivo. No quesito relativo ao zoneamento, os locais em que há maior miscigenação e variedade de usos e funções foi valorizado, e então resultou que a área da Campina do
Siqueira obteve maior pontuação pela miscigenação de usos, o que ocorre menos na área das Praças Tiradentes e Rui Barbosa. 0 quesito "área" (superfície do recorte) não foi pontuado por se considerar que, a princípio, não afeta o estudo no estágio atual.

$\mathrm{Na}$ categoria 2, se pontuaram os quesitos relativos à densidade populacional no polígono de estudo e em relação ao total da cidade e o Terminal do Cabral obteve a maior pontuação por concentrar a maior densidade de habitantes, conforme defende Nilsson et al. (2014). Esse resultado deriva da concentração de edifícios residenciais e mistos com grande número de pavimentos.

No entanto, na categoria 3, a valorização foi de aspectos puramente locais, apesar de estarem conectados ao contexto socioambiental maior. Alguns itens, como permeabilidade do solo, nível de ruído que atualmente não estão muito evidentes poderiam ter um peso maior na pontuação, assim como áreas inundáveis (Palomo, 2005). Também de igual relevância são os fatores ambientais favoráveis, sobretudo, aspectos de conforto ambiental (Campos, 
2005; Romero, 2001; Mascaró, 1996). Essa categoria analítica tem melhor solução no marco zero da cidade, a Praça Tiradentes. Já na categoria 4, os pólos geradores de tráfego são considerados fatores determinantes para a relação uso do solo e mobilidade e, portanto, possuem a pontuação mais elevada (Lima, 2010).

Na categoria 5, de equipamentos e serviços, o peso da pontuação foi igualada para educação, saúde, cultura e lazer, serviços de segurança, justiça e atendimento ao cidadão, assim como comércio. A Praça Tiradentes se destacou tanto na categoria 5 quanto na 6 por concentrar equipamentos tradicionais no tema, tais como: pontos focais, elementos de referência arquitetônica (ícones urbanos), elementos facilitadores de mobilidade, equipamentos e infraestruturas urbanas. 0 Gráfico 2 e a Tabela 1 apresentam, respectivamente, um comparativo e uma síntese da primeira aplicação da pontuação por categorias de análise.

Dos dados apresentados na Tabela 1, organizados por categorias, se observa que: quanto à localização, os locais que se situam a menos de $1,5 \mathrm{~km}$ do marco zero da cidade foram mais valorizados, por supostamente serem mais acessíveis a equipamentos e serviços de interesse coletivo. No quesito relativo ao zoneamento, os locais em que há maior miscigenação e variedade de usos e funções foi valorizado, e então resultou que a área da Campina do Siqueira obteve maior pontuação pela miscigenação de usos, o que ocorre menos na área das Praças Tiradentes e Rui Barbosa. 0 quesito "área" (superfície do recorte) não foi pontuado por se considerar que, a princípio, não afeta o estudo no estágio atual.

Tabela 1 - Categorias de análise do espaço urbano com sintese da avaliação por atribuição de pontos

\begin{tabular}{|c|c|c|c|c|c|c|c|c|c|}
\hline $\begin{array}{l}\text { Categorias / Área da } \\
\text { cidade }\end{array}$ & $\begin{array}{l}\text { Peso do } \\
\text { item }\end{array}$ & RUI BARBOSA & $\begin{array}{l}\text { Grau } \\
\text { recebido }\end{array}$ & TIRADENTES & Grau recebido & CABRAL & $\begin{array}{l}\text { Grau } \\
\text { recebido }\end{array}$ & $\begin{array}{l}\text { CAMPINA DO } \\
\text { SIQUEIRA }\end{array}$ & $\begin{array}{l}\text { Grau } \\
\text { recebido }\end{array}$ \\
\hline \multicolumn{10}{|c|}{ 1. IDENTIFICADORES - LOCALIZAÇ̃OO - ZONA - ÁREA - (Peso = 12 Pontos $)$} \\
\hline Bairro & - & Centro & - & Centro & - & Cabral & - & $\begin{array}{l}\text { Campina do } \\
\text { Siqueira }\end{array}$ & - \\
\hline Zona predominante & 6 & Zona Central ZC & 4 & Setor Histórico SH & 3 & $\begin{array}{c}\text { Zona } \\
\text { Residencial } 4 \\
\text { ZR4 + Setor } \\
\text { Estrutural SE }\end{array}$ & 5 & $\begin{array}{l}\text { ZR-1, ZR-3, } \\
\text { ZR-4, ZR-B, SE, } \\
\text { SE-NC }\end{array}$ & 6 \\
\hline $\begin{array}{l}\text { Distância do Marco Zero } \\
\text { (m) }\end{array}$ & 6 & 340 & 6 & 0 & 6 & 3114 & 5 & 3500 & 5 \\
\hline Área (hectares) & - & 39 & - & 27 & - & 62 & - & 22,3 & - \\
\hline $\begin{array}{l}\text { SUBTOTAL } \\
\text { CATEGORIA I }\end{array}$ & 12 & & 10 & & 9 & & 10 & & 11 \\
\hline \multicolumn{10}{|c|}{ 2. DEMOGRAFIA - DENSIDADE - (Peso = 12 Pontos) } \\
\hline População do polígono & - & 4.978 & - & 37.348 & - & 24.410 & - & 2.038 & - \\
\hline $\begin{array}{l}\text { População do Bairro } \\
(2010)\end{array}$ & - & 32.623 & - & 37.283 & - & 13.060 & - & 7.108 & - \\
\hline $\begin{array}{l}\text { \% Relativa à populacãa } \\
\text { de Curitiba (2010) }\end{array}$ & - & $0,27 \%$ & & 2,02 & & 1,32 & & $0,11 \%$ & \\
\hline $\begin{array}{c}\text { Densidade populacional } \\
\text { polígono (hab/ ha) }\end{array}$ & 6 & 127 & 3 & 113,56 & 3 & 393,71 & 4 & 92,16 & 2 \\
\hline $\begin{array}{l}\text { Posição relativa densida- } \\
\text { de populacional média de } \\
\text { Curitiba (40,3 hab/ha) }\end{array}$ & 6 & 3,15 vezes maior & 3 & 2,81 vezes maior & 2 & $\begin{array}{l}9,76 \text { vezes } \\
\text { maior }\end{array}$ & 5 & $\begin{array}{l}2,28 \text { vezes } \\
\text { maior }\end{array}$ & 2 \\
\hline $\begin{array}{c}\text { SUBTOTAL } \\
\text { CATEGORIA } 2\end{array}$ & 12 & & 6 & & 5 & & 9 & & 4 \\
\hline
\end{tabular}


Tabela 1 - Categorias de análise do espaço urbano com sintese da avaliação por atribuiç̃ão de pontos

\begin{tabular}{|c|c|c|c|c|c|c|c|c|c|}
\hline $\begin{array}{l}\text { Categorias/ Área da } \\
\text { cidade }\end{array}$ & $\begin{array}{c}\text { Peso do } \\
\text { item }\end{array}$ & RUI BARBOSA & $\begin{array}{l}\text { Grau } \\
\text { recebido }\end{array}$ & TIRADENTES & Grau recebido & CABRAL & $\begin{array}{l}\text { Grau } \\
\text { recebido }\end{array}$ & $\begin{array}{c}\text { CAMPINA DO } \\
\text { SIQUUERA }\end{array}$ & $\begin{array}{l}\text { Grau } \\
\text { recebido }\end{array}$ \\
\hline \multicolumn{10}{|c|}{ 3. ITENS AMBIENTAIS - TRATAMENTO ANTRÓPICO - (Peso = 12 Pontos) } \\
\hline Declividade & 3 & Plano & 3 & Plano & 3 & \begin{tabular}{|c|} 
Plano/ \\
parcialmente \\
inclinado
\end{tabular} & 2,5 & Plano & 3 \\
\hline Sistema hídrico & 3 & Drenado & 2 & Drenado & 2 & $\begin{array}{c}\text { Rio Juvevê } \\
\text { parcialmente } \\
\text { enterrado }\end{array}$ & 2 & Drenado & 2 \\
\hline $\begin{array}{l}\text { Fatores ambientais } \\
\text { favoráveis }\end{array}$ & 4 & $\begin{array}{l}\text { Área nõo inundável; } \\
\text { presença vegetacẵo } \\
\text { de porte/ ameniza- } \\
\text { ç̃o insolaç̣̃o; }\end{array}$ & 2,5 & 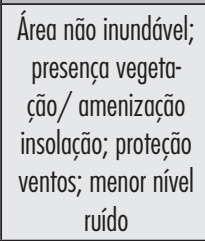 & 3 & $\begin{array}{l}\text { Transição } \\
\text { pouco acentu- } \\
\text { ada entre di- } \\
\text { ferentes niveis } \\
\text { declividade }\end{array}$ & 2 & $\begin{array}{c}\text { Baixo nível } \\
\text { poluição aérea; } \\
\text { transiçãoo pouco } \\
\text { acentuada entre } \\
\text { diferentes níveis } \\
\text { declividade }\end{array}$ & 2 \\
\hline $\begin{array}{l}\text { Fatores ambientais } \\
\text { desfavoríveis }\end{array}$ & -4 & $\begin{array}{l}\text { Alta permeabilidade } \\
\text { solo; rúdo veículos e } \\
\text { ônibus; risco aciden- } \\
\text { tes com veículos }\end{array}$ & $-1,5$ & $\begin{array}{l}\text { Alta permeabilidade } \\
\text { solo; degradacãán } \\
\text { uso edificaçōoes }\end{array}$ & -1 & $\begin{array}{l}\text { Alta permeabi- } \\
\text { li- dade solo; }\end{array}$ & -2 & $\begin{array}{c}\text { Média } \\
\text { permeabilidade } \\
\text { solo; vegetaccão } \\
\text { restrita; risco } \\
\text { acidente com } \\
\text { veículos }\end{array}$ & -2 \\
\hline $\begin{array}{c}\text { Elementos vegetais/ } \\
\text { paisagismo }\end{array}$ & 2 & $\begin{array}{l}\text { Paisagismo } \\
\text { árvores/ praça/ } \\
\text { floreiras }\end{array}$ & 1,5 & $\begin{array}{c}\text { Paisagismo } \\
\text { árvores/ canteiros/ } \\
\text { árvores tombadas } \\
\text { (Araucárias - árvore } \\
\text { símbolo do Paraná) }\end{array}$ & 1,8 & $\begin{array}{l}\text { Inexistente } \\
\text { no terminal/ } \\
\text { esparsa no } \\
\text { recorte }\end{array}$ & 0 & $\begin{array}{l}\text { Árvores espar- } \\
\text { sas, eventuais }\end{array}$ & 0 \\
\hline SUBTOTAL CATEGORIA 3 & 12 & & 7,5 & & 8,8 & & 4,5 & & 5 \\
\hline \multicolumn{10}{|c|}{ 4. CIRCULAÇÃO DE ÔNIBUS - FOCO GERADOR DE TRÁfFEG - (Peso = 20 Pontos) } \\
\hline $\begin{array}{l}\text { Número de linhas de } \\
\text { onibus }\end{array}$ & 5 & 58 & 4 & 48 & 4 & 20 & 3 & 17 & 2 \\
\hline \multirow{2}{*}{$\begin{array}{l}\text { Número de ônibus em } \\
\text { circulação nos horários } \\
\text { de pico }\end{array}$} & \multirow[t]{2}{*}{7} & 07h30-08h30: 218 & \multirow[t]{2}{*}{7} & $\begin{array}{c}\text { 07h30-08h30: } \\
189\end{array}$ & \multirow[t]{2}{*}{6} & $\begin{array}{c}07 h 30- \\
-08 h 30: 187\end{array}$ & \multirow[t]{2}{*}{6} & $\begin{array}{c}\text { 07h30-08h30: } \\
130\end{array}$ & \multirow[t]{2}{*}{5} \\
\hline & & 18h-19h: 204 & & 18h-19h: 169 & & 18h-19h:169 & & 18h-19h:114 & \\
\hline Local gerador de tráfego & 8 & $\begin{array}{c}\text { Hospital, Instituicicão } \\
\text { ensino ( } 2^{\circ} \text { graue e } \\
\text { superior), comércio } \\
\text { popular }\end{array}$ & 7 & $\begin{array}{l}\text { Catedral, centro uni- } \\
\text { versitário, comércio } \\
\text { tradicional, bancos, } \\
\text { instituiçóes públicas } \\
\text { e privadas culturais }\end{array}$ & 6 & $\begin{array}{l}\text { Justiça Federal; } \\
\text { Associação } \\
\text { Paranaense de } \\
\text { Reabilitacão } \\
\text { APR }\end{array}$ & 5 & $\begin{array}{l}\text { Colégio Ensino } \\
\text { Médio e Adulto, } \\
\text { Ensino Superior; } \\
\text { supermercado }\end{array}$ & 4 \\
\hline SUBTOTAL CATEGORIA 4 & 20 & & 18 & & 16 & & 14 & & 11 \\
\hline \multicolumn{10}{|c|}{ 5. CATEGORIA EQUIPAMENTOS - SERVIICOS - (Peso $=20$ Pontos $)$} \\
\hline Educação & 4 & 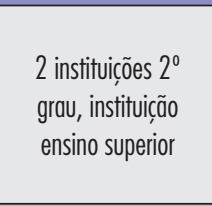 & 4 & \begin{tabular}{|c|}
3 centros univer- \\
sitários, 4 escolas \\
segundo grau, 2 \\
escolas especializa- \\
das adultos
\end{tabular} & 4 & $\begin{array}{l}\text { Escola especial } \\
\text { reabilitacã̃o } \\
\text { (Nabil Tacla) }\end{array}$ & 1 & $\begin{array}{l}\text { Colégio Ensino } \\
\text { Médio, Ensino } \\
\text { de Adultos, } \\
\text { Ensino Superio }\end{array}$ & 2 \\
\hline Saúde & 4 & $\begin{array}{l}2 \text { Hospitais privados, } \\
1 \text { Maternidade } \\
\text { privada }\end{array}$ & 4 & $\begin{array}{l}2 \text { unidades de } \\
\text { saúde pública }\end{array}$ & 1 & $\begin{array}{c}\text { Clinica } \\
\text { fisioterapia } \\
\text { deficientes } \\
\text { físicos (APR) }\end{array}$ & 1 & $\begin{array}{l}\text { Unidade munici- } \\
\text { pal de Saúde }\end{array}$ & 1 \\
\hline
\end{tabular}


Tabela 1 - Categorias de análise do espaço urbano com sintese da avaliação por atribuição de pontos

\begin{tabular}{|c|c|c|c|c|c|c|c|c|c|}
\hline $\begin{array}{l}\text { Categorias / Área da } \\
\text { cidade }\end{array}$ & $\begin{array}{l}\text { Peso do } \\
\text { item }\end{array}$ & RUI BARBOSA & $\begin{array}{l}\text { Grau } \\
\text { recebido }\end{array}$ & TIRADENTES & Grau recebido & CABRAL & $\begin{array}{l}\text { Grau } \\
\text { recebido }\end{array}$ & $\begin{array}{l}\text { CAMPINA DO } \\
\text { SIQUEIRA }\end{array}$ & $\begin{array}{l}\text { Grau } \\
\text { recebido }\end{array}$ \\
\hline \multicolumn{10}{|c|}{ 5. CATEGORIA EQUIPAMENTOS - SERVIÇOS -(PesO = 20 Pontos) } \\
\hline Cultura & \multirow[t]{2}{*}{4} & $\begin{array}{l}\text { Igreja Matriz, } \\
\text { calçadão, }\end{array}$ & \multirow[t]{2}{*}{1,5} & $\begin{array}{l}\text { Catedral, } 3 \text { igrejas, } \\
\text { sinagoga, conser- } \\
\text { vatório musical, } \\
\text { biblioteca pública, } \\
\text { centro cultural, } \\
\text { restaurantes }\end{array}$ & \multirow[t]{2}{*}{4} & - & \multirow[t]{2}{*}{0} & Igreja & \multirow[t]{2}{*}{1,5} \\
\hline Lazer & & Praça & & $\begin{array}{l}\text { Praça, calçadão, } \\
\text { feiras ao ar livre }\end{array}$ & & & & $\begin{array}{l}\text { Casa da Leitura } \\
\text { (Biblioteca e } \\
\text { sala leitura } \\
\text { municipal) }\end{array}$ & \\
\hline $\begin{array}{l}\text { Serviços de Segurança } \\
\text { pública e justiça }\end{array}$ & \multirow{2}{*}{4} & Corpo de Bombeiros & \multirow{2}{*}{3} & \multirow{2}{*}{ - } & \multirow{2}{*}{0} & \multirow{2}{*}{$\begin{array}{l}\text { Secccão da } \\
\text { Justiça federal, } \\
\text { Polícia Militar } \\
\text { do Paraná }\end{array}$} & \multirow{2}{*}{2} & \multirow{2}{*}{ - } & \multirow{2}{*}{0} \\
\hline $\begin{array}{c}\text { Atendimento ao cidadão/ } \\
\text { Gestão }\end{array}$ & & Rua da Cidadania & & & & & & & \\
\hline Comércio grande público & 4 & $\begin{array}{l}\text { Mercado hortifruti } \\
\text { (Prefeitura) }\end{array}$ & 4 & $\begin{array}{c}\text { Comércio tradicional } \\
\text { popular }\end{array}$ & 3 & $\begin{array}{l}\text { Postos de } \\
\text { abastecimento, } \\
\text { comércio } \\
\text { variado }\end{array}$ & 1 & $\begin{array}{l}\text { Supermercado, } \\
\text { comércio luxo }\end{array}$ & 1 \\
\hline SUBTOTAL CATEGORIA 5 & 20 & & 16,5 & & 12 & & 5 & & 5,5 \\
\hline \multicolumn{10}{|c|}{ 6. CATEGORIA ELEMENTOS ESPACIAIS - Forma e referências visuais - (Peso = 20 Pontos) } \\
\hline $\begin{array}{l}\text { Ponto focal (nivel } \\
\text { pedestre) }\end{array}$ & 5 & Igreja Matriz & 4 & Catedral & 5 & - & 0 & $\begin{array}{l}\text { Linha ônibus } \\
\text { BRT }\end{array}$ & 2 \\
\hline $\begin{array}{l}\text { Elemento físico/visual de } \\
\text { referência (skyline) }\end{array}$ & 5 & Torre da igreja & 4 & Torre da catedral & 4 & $\begin{array}{l}\text { Edificações } \\
\text { variadas }\end{array}$ & 1 & $\begin{array}{l}\text { Edificações } \\
\text { variadas }\end{array}$ & 1 \\
\hline $\begin{array}{c}\text { Elemento facilitador da } \\
\text { mobilidade }\end{array}$ & 10 & $\begin{array}{c}\text { Trama de ruas } \\
\text { largas/ centalidade }\end{array}$ & 9 & $\begin{array}{l}\text { Calccadão, quadras } \\
\text { curtas, possível } \\
\text { ciclovia, favorável } \\
\text { p/ mobilidade a pé }\end{array}$ & 8 & $\begin{array}{l}\text { Malha viária } \\
\text { compatível } \\
\text { com fluxo }\end{array}$ & 7 & Malha viária & 9 \\
\hline $\begin{array}{l}\text { Elemento dificultador da } \\
\text { mobilidade }\end{array}$ & -10 & $\begin{array}{c}\text { Inexistência } \\
\text { separação para } \\
\text { veículos não motori- } \\
\text { zados, inexistência } \\
\text { bicicletário, esquema } \\
\text { uni-modal }\end{array}$ & -6 & $\begin{array}{l}\text { Ruas estreitas, } \\
\text { quadras curtas, } \\
\text { traçado viário } \\
\text { sinuoso; inexistência } \\
\text { bicicletário, esque- } \\
\text { ma uni-modal }\end{array}$ & -4 & $\begin{array}{l}\text { Inexistência } \\
\text { separaccão para } \\
\text { veículos não } \\
\text { motorizados; } \\
\text { inexistência } \\
\text { bicicletário, } \\
\text { esquema } \\
\text { uni-modal }\end{array}$ & -6 & $\begin{array}{l}\text { Inexistência } \\
\text { separaccão para } \\
\text { veículos não } \\
\text { motorizados; } \\
\text { inexistência } \\
\text { de bicicletário, } \\
\text { esquema uni- } \\
\text {-modal }\end{array}$ & -6 \\
\hline SUBTOTAL CATEGORIA 6 & 20 & & 11 & & 13 & & 2 & & 6 \\
\hline TOTAL $=96$ & & \multicolumn{2}{|c|}{ RUI BARBOSA } & \multicolumn{2}{|c|}{ TIRADENTES } & \multicolumn{2}{|c|}{ CABRAL } & \multicolumn{2}{|c|}{ CAMPINA DO SIQUEIRAT } \\
\hline
\end{tabular}

Fonte: Elaborado pelos autoras.

Na categoria 2, se pontuaram os quesitos relativos à densidade populacional no polígono de estudo e em relação ao total da cidade e o Terminal do Cabral obteve a maior pontuação por concentrar a maior densidade de habitantes, conforme defende Nilsson et al. (2014). Esse resultado deriva da concentração de edifícios residenciais e mistos com grande número de pavimentos.
No entanto, na categoria 3, a valorização foi de aspectos puramente locais, apesar de estarem conectados ao contexto socioambiental maior. Alguns itens, como permeabilidade do solo, nível de ruído que atualmente não estão muito evidentes poderiam ter um peso maior na pontuação, assim como áreas inundáveis (Palomo, 2005). Também de igual relevância são os fatores ambientais favoráveis, sobretudo, aspectos de conforto 
ambiental (Campos, 2005; Romero, 2001; Mascaró, 1996). Essa categoria analítica tem melhor solução no marco zero da cidade, a Praça Tiradentes. Já na categoria 4, os pólos geradores de tráfego são considerados fatores determinantes para a relação uso do solo e mobilidade e, portanto, possuem a pontuação mais elevada (Lima, 2010).

Na categoria 5, de equipamentos e serviços, o peso da pontuação foi igualada para educação, saúde, cultura e lazer, serviços de segurança, justiça e atendimento ao cidadão, assim como comércio. A Praça Tiradentes se destacou tanto na categoria 5 quanto na 6 por concentrar equipamentos tradicionais no tema, tais como: pontos focais, elementos de referência arquitetônica (ícones urbanos), elementos facilitadores de mobilidade, equipamentos e infraestruturas urbanas. 0 Gráfico 2 e a Tabela 2 apresentam, respectivamente, um comparativo e uma síntese da primeira aplicação da pontuação por categorias de análise.

Os resultados apresentados no Gráfico 2 e na Tabela 2 atestam as melhores condições do terminal da Praça Rui Barbosa, devido a se situar próximo ao Marco Zero da cidade, supostamente o local mais central com equipamentos tradicionalmente utilizados em Curitiba e acessíveis para a população. Seu zoneamento é variado (uso residencial, comercial, serviços, lazer, cultura), exceto a função industrial, e apresenta alta densidade residencial, apesar de algum esvaziamento tanto no uso residencial quanto variação do tipo de comércio. A avaliação dos itens ambientais e modificações antrópicas demonstrou que esse terminal é o melhor de todos, devido às boas condições quanto às declividades, permeabilidade do solo, controle de enchentes e a presença de áreas verdes.

Gráfico 2 - Comparativo dos resultados da avaliação do desenho urbano dos terminais Rui Barbosa, Tiradentes, Cabral e Campina do Siqueira - dados 2014

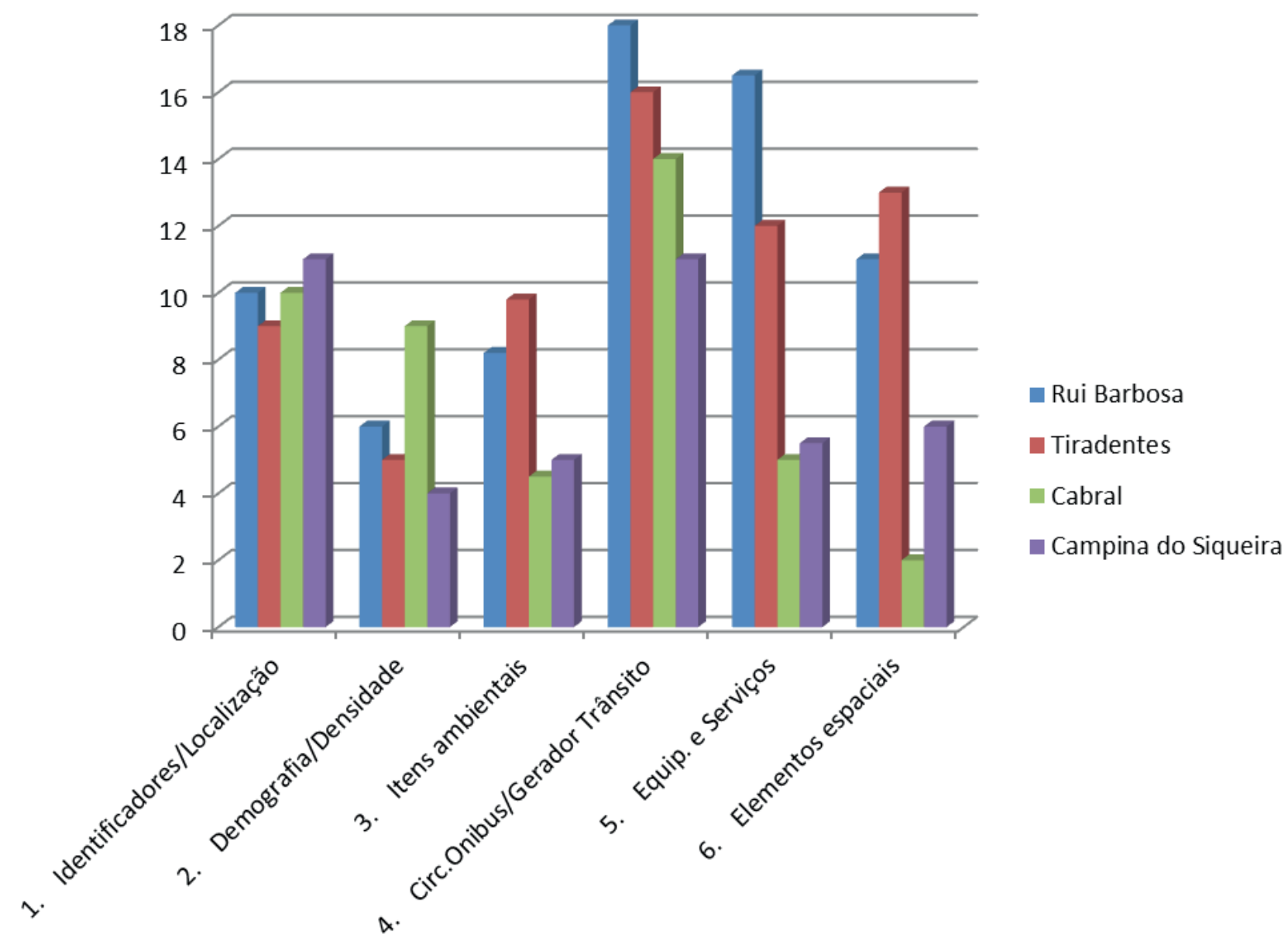

Fonte: Elaborado pelos autoras. 
Tabela 2 - Síntese dos resultados da avaliação do desenho urbano dos terminais Rui Barbosa, Tiradentes, Cabral e Campina do Siqueira - dados 2014

\begin{tabular}{|c|c|c|c|c|c|}
\hline Categorias/Terminais & Peso categoria & Rui Barbosa & Tiradentes & Cabral & Campina do Siqueira \\
\hline 1. Identificadores/Localização & 12 & 10 & 9 & 10 & 11 \\
\hline 2. Demografia/Densidade & 12 & 6 & 5 & 9 & 4 \\
\hline 3. Itens ambientais & 12 & 8,2 & 9,8 & 4,5 & 5 \\
\hline 4. Circ. Ônibus/Gerador Trânsito & 20 & 18 & 16 & 14 & 11 \\
\hline 5. Equip. e Servicos & 20 & 16,5 & 12 & 5 & 5,5 \\
\hline 6. Elementos espaciais & 20 & 11 & 13 & 2 & 6 \\
\hline Subtotal & 96 & 69,7 & 64,8 & 44,5 & 42,5 \\
\hline \% do total & 100 & 72,6 & 67,5 & 46,35 & 44,27 \\
\hline $\begin{array}{c}\text { NOTA REFERENCIA } \\
\text { DO TERMINAL. }\end{array}$ & $\mathbf{1 0}$ & $\mathbf{7 , 2}$ & $\mathbf{6 , 7}$ & $\mathbf{4 , 6}$ & $\mathbf{4 , 4}$ \\
\hline
\end{tabular}

Fonte: Elaboração própria.

É o maior terminal do município quanto ao número de ônibus (linhas e veículos), estando bem situado em relação à acessibilidade dos usuários de ônibus aos serviços públicos de saúde, educação, comércio e serviços. E, finalmente, o local possui elementos espaciais que oferecem referências visuais e identitárias aos usuários, oferece boas condições de mobilidade para vários modais - a pé, bicicleta, ônibus, automóvel, e boa sinalização de trânsito. Os demais terminais aqui apresentados foram avaliados segundo os mesmos critérios.

A análise dos dados em relação com o marco teórico permite algumas considerações, que serão apresentadas a seguir.

\section{Considerações finais}

Os resultados mostrados no artigo conformam um substrato em desenvolvimento, não obrigatoriamente para um modelo ou padrão de desenho urbano a ser aplicado em todas as áreas de entorno de terminais - ou casos similares, mas para definir indicadores decorrentes da aplicação de categorias de análise e critérios de avaliação de determinados componentes do espaço. Por meio da aplicação dessas categorias de análise, que no presente estágio ainda são iniciais e gerais, se pretende uma primeira avaliação das condições do espaço do entorno de terminais, com foco no uso físico do espaço. Assim, talvez de forma ainda muito simplificada, no presente estágio do trabalho foram atribuidas "Notas-Referência" para cada terminal, a fim de possibilitar seu posicionamento no conjunto de locais submetidos à gestão pública, no espaço urbano municipal.
Os terminais foram aqui considerados como espaços privilegiados dos Eixos Estruturais, elementos emblemáticos do Desenho Urbano da cidade e de uso efetivo e intenso pela população. Os espaços dos terminais são fatores de atração e também de dispersão dos usuários do sistema de transporte, situados em locais onde pode haver incremento da vinculação entre sistema de transporte e acessibilidade econômica dos usuários do sistema, aos imóveis do entorno. Esse custo imobiliário será anexado nas etapas seguintes, assim como a validade promovida como indicado nas considerações metodológicas, incluindo consulta com profissionais do planejamento e gestão.

0 recorte proposto aqui, apesar de restrito, oferece material para a sequência direcionada a procedimentos mais avançados como análise multicritério, definição de indicadores e pontuação para cada espaço, aplicando a metodologia e aprofundamento do estudo sobre a importância dos referenciais visuais e a legibilidade do espaço urbano. Considera-se o resultado dessa avaliação como potencial para subsidiar o processo de tomada de decisão da gestão pública, especificamente quanto à avaliação de espaços existentes em relação à necessidade de intervenção urbana, como mudar características de uso e ocupação, especialmente densidade, renovar as instalações, otimizar qualidades espaciais e ambientais, incluindo a integração com projetos pludisciplinares, como e inserção social.

A etapa da pesquisa se mostrou válida para compreensão de necessidades e potencialidades do local. Finalmente, as interrogações sobre a relação entre expansão urbana e disponibilidade de sistema de transporte são complexas e demandam aproximações 
gradativas a serem realizadas. A avaliação do desempenho de espaços urbanos, como os que existem no entorno de terminais dos ônibus BRT de Curitiba, pode contribuir para otimizar os investimentos públicos, enquanto planejamento, gestão e aplicação de recursos ambientais e financeiros. Este artigo apresenta um direcionamento voltado para definir métodos a serem usados por arquitetos urbanistas para avaliação dos resultados de espaços existentes, a fim de lhes fornecer fundamentos alternativos na criação de novos espaços. Trata-se de metodologia em construção que nas etapas subsequentes deve buscar adaptação de métodos existentes como o AHP (Analytical Hierarchical Process) conforme Vargas (1990), Rafaeli \& Müller (2007) para avaliação multicritério que articulem variáveis objetivas com outras de cunho sociocultural, como é o caso de espaços urbanos.

\section{Agradecimentos}

Aos estudantes bolsistas e voluntários do Programa de Iniciação Científica que interagem no âmbito do Projeto Ignis Mutat Res, do DAU/UFPR, pela contribuição de imagens provenientes das pesquisas individuais dos mesmos nos anos 2014 e 2015.

\section{References}

Allain, R. (2004). Morphologie urbaine. Paris: Armand Colin.

Allaire, J. (2006). Choisir son mode de ville: formes urbaines et transports dans les villes émergentes. Les Cahiers de global chance, (21), 66-70.

Amado, M. P. (2009). Planeamento urbano sustentável. (2 $2^{\mathrm{a}}$ ed.). Portugal: Caleidoscópio.

Arrais, T. A. (2005). Mobilidade e centralidade. In A. MOYSÉS (Eds.), Cidade, segregação e planejamento (p. 347-355). Goiânia: Editora da UCG.

Ascher, F. (2010). Les nouveaux principes de l'urbanisme. Paris: de l'Aube.

Bispo Neto. (2013). Sistema de transporte de Curitiba tem 401 articulados e biarticulados Volvo. Jornal Paraná online, 19, 1. Recuperado em 08 de fevereiro de 2015, de http://www.parana-online.com.br.
Brasil (2012, 04 de janeiro). Lei n. 12.587, de 03 de janeiro de 2012. Institui as diretrizes da Política Nacional de Mobilidade Urbana; revoga dispositivos dos DecretosLeis nos 3.326, de 3 de junho de 1941, e 5.405, de 13 de abril de 1943, da Consolidação das Leis do Trabalho (CLT), aprovada pelo Decreto-Lei no 5.452, de 1 o de maio de 1943, e das Leis nos 5.917, de 10 de setembro de 1973, e 6.261, de 14 de novembro de 1975; e dá outras providências. Brasília: Diário Oficial da União, seção 1.

Brasil (2015, 13 de janeiro). Lei n. 13.089, de 12 de janeiro de 2015. Institui o Estatuto da Metrópole, altera a Lei no 10.257, de 10 de julho de 2001, e dá outras providências. Brasília: Diário Oficial da União, seção 1.

Campos, R. F. (2005). Análise da influência da orientação da testada dos lotes na ocupação do setor estrutural de Curitiba. (Dissertação de mestrado). Construção Civil, Universidade Federal do Paraná, Curitiba.

Campos, V. B. G, Ramos, R.A. (2005). Proposta de indicadores de mobilidade urbana sustentável relacionando transporte e uso do solo. In Anais do $1^{\text {o }}$ Congresso Luso Brasileiro para o Planejamento Urbano Regional Integrado Sustentável (p. 1-12). São Carlos: PLURIS.

Cara, L. F. P. (2014). Relatório Final de Iniciação Científica. Curitiba: UFPR.

Cassirer, E. (2011). A filosofia das formas simbólicas. (Terceira Parte). São Paulo: Martins Fontes.

Chatfield, C., \& Collins, A. J. (1992). Introduction to multivariate analysis. Cambrige: University Press.

Choay, F. (2006). Pour une anthropologie de l'espace. (1.ed.). Paris: du Seuil.

Comec (2006). Plano de desenvolvimento da Região Metropolitana de Curitiba: propostas de ordenamento territorial e novo arranjo institucional. Curitiba: Coordenação da Região Metropolitana de Curitiba.

Costa, A. P. S. (2007). 0 estudo da forma urbana no Brasil. Arquitextos, 87(5). Recuperado em 20 de setembro de 2016, de http://www.vitruvius.com.br.

Curitiba (2008, 24 de março). Lei n. 12.597, de 24 de março de 2008. Dispõe sobre a organização do sistema de transporte coletivo da cidade de Curitiba, autoriza o poder público a delegar a sua execução, e dá outras providências. Curitiba: Diário Oficial do Município de Curitiba, seção 1. 
Curitiba (2004, 16 de dezembro). Lei n. 11.266, de 16 de dezembro de 2004. Dispõe sobre a adequação do Plano Diretor de Curitiba ao Estatuto da Cidade - Lei Federal no $10.257 / 01$, para orientação e controle do desenvolvimento integrado do Município. Curitiba: Diário Oficial do Município de Curitiba, seção 1.

Curitiba (2000, 3 de janeiro). Lei n. 9.800, de 3 de janeiro de 2000. Dispõe sobre o zoneamento, uso e ocupação do solo no município de Curitiba, revoga as leis n.4.199/72, 5.234/75, 5.263/75, 5.490/76, 6.204/81, 6.769/85, 7.068/87 e 7.622/91, e dá outras providências. Curitiba: Diário Oficial do Município de Curitiba, seção 1.

Daniels, R. \& Mulley, C. (2011) Explaining walking distance to public transport: the dominance of public transport supply. In Anais de World Symposium Transport Land Use Research 2011, (s. p.) Whistler (Canada): WSTLUR. Recuperado em 20 de janeiro de 2015, de http://sydney.edu.au/business/_data/assets/pdf_file/ 0013/106501/Daniels-Mulley-Explaining.pdf.

Demo, P. (1995). Metodologia científica em Ciências Sociais. São Paulo: Atlas.

Dresch, A., Lacerda, D. P., \& Antunes Jr., J. A. (2015). Design Science Research. A method for Science and Technology Advancement. New York: Springer.

Flick, U. (2009). Qualidade na pesquisa qualitativa. Porto Alegre: Artmed.

Freyman, M. (2012). An Exploration of Sustainability and its Application to Corporate Reporting. Cambridge: Harvard University.

Frugoli Junior, H. (2000). Centralidade em São Paulo. São Paulo: Cortez; Edusp.

Hertzberger, H. (1999). Lições de Arquitetura. São Paulo: Martins Fontes.

Ibge (1996). Contagem populacional. Rio de Janeiro: Instituto Brasileiro de Geografia e Estatística.

Kates, R. W., Parris, T. M., \& Leiserowitz, A. (2005). What's Sustainable Development. Environment: Science and Policy for Sustainable Development, 47(3), 8-21.

Kenworthy, J., \& Laube, F. B. (1999). Patterns of automobile dependence in cities: an international overview of key physical and economic dimensions with some implications for urban policy. Transportation Research, 33(A), 691-723.
Kohlsdorf, M. E. (1996). A apreensão da forma da cidade. Brasília: UnB.

Lamas, J. R. G. (2000). Morfologia urbana e desenho da cidade. Lisboa: Calouste Gulbenkian.

Lima, C. de A. (2015). Configuração urbana e o sistema BRT de Curitiba - Brasil. In Anais do VII Seminário Internacional de Investigação em Urbanismo (s. p.). Barcelona: VIISIIU.

Lima, C. de A. (2010). Ignis mutat res: cidade, mobilidade, energia e governança. (Projeto de pesquisa aprovado pelo Departamento Arquitetura e Urbanismo). Curitiba: UFPR.

Lima, C. de A. (2000). A ocupação urbana em área de mananciais: do planejamento à gestão ambiental urbana-metropolitana. (Tese de doutorado). Meio Ambiente e Desenvolvimento, Universidade Federal do Paraná, Curitiba.

Lynch, K. (1997). A imagem da cidade. São Paulo: Martins Fontes.

Marconi, M. A. \& Lakatos, E. M. (2004). Metodologia científica. São Paulo: Atlas.

Mascaró, L. R. (1996). Adensamento e ambiência urbana na cidade de Porto Alegre. In Anais do Núcleo de Pesquisa em Tecnologia da Arquitetura e Urbanismo de 1996: Seminário Internacional (p. 427-441). São Paulo: NUTAU'96.

Mongin, O. (2013). La ville des flux. Paris: Fayard.

Neuman, M. (2014). The compact city fallacy. Recuperado em 24 de abril de 2016, de http://understandtheplan.info/wp-content/uploads/2014/08/The-Compact-City-Fallacy.pdf.

Nilsson, K., Nielsen, T. S., Albers, C., Bell, S., \& Boitier, B. (2014). The European Journal of Spatial Development. Recuperado em 24 de abril de 2016, de http://www.nordregio.se/ Global/EJSD/Research briefings/article4.pdf.

Nobre, E. (2011). Desenho Urbano. Por Uma Definição. São Paulo: FAU-USP. Recuperado em 01 de fevereiro de 2015, de http://www.fau.usp.br/docentes/depprojeto /e_nobre/AUP573/aula1.pdf.

Palomo, P. S. (2005). La planificación verde en las ciudades. Barcelona: Gustavo Gili.

Prefeitura Municipal de Curitiba (2016). Biocidade. Recuperado em 24 de abril de 2016, de http://www. biocidade.curitiba.pr.gov.br/biocity/33.html.

Pouyanne, G. (2004). Urban form and daily mobility: methodological aspects and empirics study. European Transport \Trasporti Europei, 44(2010), 76-95. 
Prevedello, A. A. (2014). Diretrizes de Uso e Ocupação do Solo. Estudo de Caso da Linha Verde de Curitiba Paraná. (Dissertação de mestrado). Construção Civil, Universidade Federal do Paraná, Curitiba.

Rafaeli, L., \& Müller, C. J. (2007). Estruturação de um índice consolidado de desempenho utilizando o AHP. Gestão \& Produção, 14(2), 363-377. doi: dx.doi. org/10.1590/S0104-530X2007000200013

Robson, C. (2011). Real world research. Cornwall (Reino Unido): Wiley.

Romero, M. A. B. (2001). Arquitetura bioclimática do espaço público. Brasília: UnB.

Santos, R. F. (2004). Planejamento ambiental: teoria e prática. São Paulo: Oficina de Textos.

Silveira, L. S. da C. (2012). Determinação de Índice da situação do transporte (Tese de doutorado). Faculdade de Tecnologia, Universidade de Brasília, Brasília. Recuperado em 20 de setembro de 2016, de http://www. transportes.unb.br/downloads/teses/002A-2012.pdf
Tucci, C. E. M., \& Bertoni, C. (org.) (2003). Inundações urbanas na América do Sul. Porto Alegre: Edição dos Autores.

Vallejo, M. H., \& Farrerons, J. M. (2002). El soporte infrastructural de la ciudad. Barcelona: Edicions UPC.

Vargas, L. G. (1990). An Overview of the Analytic Hierarchy Process and its Applica- tions. European Journal of Operational Research, 48, 2-8.

Yin, R. K. (2005). Estudo de caso: planejamento e métodos. (3a. ed.). Porto Alegre: Bookman.

Recebido: Nov. 15, 2016

Aprovado: Mar. 16, 2017 